that they never smoked, $12(7 \cdot 2 \%)$ had reported being a current or ex-smoker in 1980 . Of 174 who had said in 1980 that they never smoked, $22(12.6 \%)$ said in 1985 that they had smoked before 1980 . Such subjects tended to be light smokers and to be ex-smokers, often long term.

The final study, based on 8857 representative UK subjects interviewed in 1985, allowed the joint smoking habit distribution of married couples to be estimated (table II), showing strong concordance.

TABLE I-Cotinine values ${ }^{\star}$ according to self reported smoking category

\begin{tabular}{|c|c|c|c|c|}
\hline \multirow{2}{*}{$\begin{array}{l}\text { Salivary } \\
\text { cotinine } \\
\text { (ug 1) }\end{array}$} & \multicolumn{2}{|c|}{ Non-smokers } & \multicolumn{2}{|c|}{ Smokers $\$$} \\
\hline & Male & Female & Male & Female \\
\hline & No $(\%)$ & $\mathrm{No}(\%)$ & No $(\%)$ & No $(\%)$ \\
\hline$<0.1$ & $84(24)$ & $136(30)$ & 0 & $2(2 \cdot 8)$ \\
\hline $0 \cdot 1-$ & $24(7)$ & $52(11)$ & 0 & 0 \\
\hline $0 \cdot 3$ & $78(22)$ & $122(27)$ & 0 & $1(1.4)$ \\
\hline $1 \cdot 0$ & $100(29)$ & $92(20)$ & $1(1 \cdot 0)$ & 0 \\
\hline $3 \cdot 0-$ & $45(13)$ & $41\langle 9 \cdot 0\rangle$ & $6(5 \cdot 8)$ & 0 \\
\hline $10 \cdot 0$ & $9(2 \cdot 6)$ & $5(1 \cdot 1)$ & $54 \cdot 8$ & 0 \\
\hline $30 \cdot 0$ & $4(1 \cdot 1) t$ & $5(1 \cdot 1) t$ & $6(5 \cdot 8)$ & $3(4 \cdot 2)$ \\
\hline $100 \cdot 0$ & $+(1 \cdot 1)=$ & $3(0 \cdot 7) \neq$ & $28(27)$ & $24(33)$ \\
\hline $300 \cdot 0-$ & $2(0 \cdot 6) \neq$ & $2(0 \cdot 4) \neq$ & $58(56)$ & $42(58)$ \\
\hline \multirow[t]{2}{*}{ All } & $350(100)$ & $458(100)$ & $104(100)$ & $72(100)$ \\
\hline & $\mu g / l$ & $\mu g l$ & $\mu g / l$ & $\mu g / l$ \\
\hline Medi & $0 \cdot 85$ & 0.40 & $319 \cdot 2$ & 310.6 \\
\hline Mean & 6.69 & $5 \cdot 31$ & $331 \cdot 0$ & $332 \cdot 2$ \\
\hline \multirow{2}{*}{$\begin{array}{l}\text { Mean (excluding } \\
\text { non smokers } \\
>30 \mathrm{ng} / \mathrm{ml} \text { ) }\end{array}$} & & & & \\
\hline & 1.64 & $1 \cdot 16$ & $331 \cdot 0$ & $332 \cdot 2$ \\
\hline
\end{tabular}

*Available for $95 \%$ of non-smokers and $26 \%$ of smokers. †Nine "occasional smokers" with values $38 \cdot 9-87 \cdot 8 \mu \mathrm{g} / \mathrm{l}$ †Eleven "regular smokers" with values $132 \cdot 2-473 \cdot 5 \mu \mathrm{g} / \mathrm{L}$. §Includes smokers, users of other nicotine containing products, and non-smokers who reported having smoked in the last 7 days.

TABLE II-Estimated self reported smoking habit distribution for 10000 UK married couples

\begin{tabular}{lcccc}
\hline & \multicolumn{3}{c}{ Women } & \\
\cline { 2 - 4 } Men & $\begin{array}{c}\text { Never } \\
\text { smoked }\end{array}$ & Ex-smoker & $\begin{array}{c}\text { Current } \\
\text { smoker }\end{array}$ & Total \\
\hline Never smoked & 1656 & 386 & 531 & $25 \cdot 7 \%$ \\
Ex-smoker & 1352 & 802 & 619 & $27 \cdot 7 \%$ \\
Current smoker & 1822 & 624 & 2208 & $46 \cdot 5 \%$ \\
\hline Total & $48 \cdot 3 \%$ & $18 \cdot 1 \%$ & $33 \cdot 6 \%$ & $100 \cdot 0 \%$
\end{tabular}

Concordance ratios: never smoked/ex-smoker $2 \cdot 54$, never smoked/current smoker $3 \cdot 78$

Assuming that those who report that they have never smoked include $1.4 \%$ regular smokers (relative risk $(R R)=10), 1 \cdot 1 \%$ occasional smokers $(R R=2 \cdot 5)$, $10 \%$ ex-smokers $(\mathrm{RR}=2)$, and $87 \cdot 5 \%$ never smokers $(\mathrm{RR}=1)$, I estimate that if passive smoking were without effect there would be an excess risk of lung cancer associated with a spouse smoking of $31 \%$ in men and $24 \%$ in women. This bias derives mainly from misclassified regular smokers, not observed by Professor Wald and colleagues. The bias is much larger than estimates of excess risk ( $7 \%$ in men, $2 \%$ in women) derived from linear extrapolation of cotinine values in relation to active smoking and smoking by a spouse.

Since the dose relation may have a quadratic component ${ }^{5}$ and cotinine may substantially overestimate relative exposure to particulate matter of passive and active smokers (Arundel A, et al, unpublished observations), it seems that the $20-50 \%$ excess risk of lung cancer associated with a spouse smoking is much too high to be explained dosimetrically. I conclude that it is predominantly due to bias.

Peter N Lee

Sutton,

Surrey SM2 5DG
1 Lee PN. Passive smoking. In: Cumming G, Bonsignore G, eds. Smoking and the lung. New York: Plenum Publishing, 1984 187-216.

2 Wells AJ. Misclassification as a factor in passive smoking risk. Lancet 1986;ii:638.

3 Lehnert G, Garfinkel L, Hirayama T, et al. Round table discussion on medical perspectives on passive smoking (Vienna, discussion on medical perspectives on pas

+ Feverabend C, Russell MAH. Rapid gas-liquid chromatographic Feverabend C, Russell MAH. Rapid gas-liquid chromatographic
determination of cotinine in biological fluids. Analyst 1980;105: 998-1001.

5 Doll R, Peto R. Cigarette smoking and bronchial carcinoma: dose and time relationships among regular smokers and lifelong non-smokers. F Epidemiol Community Health 1978;32:303-13.

\section{Pelvic pain in women}

SIR,-The algorithm devised by Professor R W Beard and his colleagues (1 November, p 1161) recommends that if a woman complains of recurrent pelvic pain unrelated to menstruation and she denies deep dyspareunia or postcoital ache then the GP should look for "evidence of nongynaecological pathology." If this is not found the patient should be referred to a gynaecologist.

This begs the question of what constitutes "evidence of non-gynaecological pathology." If it is taken to mean objective abnormalities on physical examination then, I fear, this algorithm could provoke a flood of unnecessary referrals to gynaecologists.

Apart from dysmenorrhoea, the commonest cause of lower abdominal pain (surely a better term than pelvic pain) is irritable bowel syndrome. Among 301 apparently healthy people in Bristol and Portsmouth we found $31(10.3 \%)$ who admitted to recurrent lower abdominal pain in the previous year. ${ }^{1}$ In most of these the pain was relieved by defecation and there were other symptoms of irritable bowel syndrome. The survey included 49 young women (trainee nurses). Of these, no fewer than $13(26.5 \%)$ admitted to irritable bowel type pains.

Irritable bowel syndrome does not reliably cause physical signs. If the doctor is to find "evidence of non-gynaecological pathology" in these patients it is by taking an appropriate history. ${ }^{2}$ Specifically, the doctor must ask if the pain is relieved by defecation or if episodes of pain are associated with a change in bowel habit. Usually this change is towards looser and more frequent stools, but it is not necessarily complained of since it may be welcomed as relief of a previously constipated habit. Additional pointers to the diagnosis of irritable bowel are distension or bloated feelings, feelings of incomplete evacuation, and the passage of mucus per rectum

Unless such a history is taken many women will be labelled wrongly as having "unexplained abdominal pain." Like the cases of pelvic pain syndrome discussed by Professor Beard and his colleagues patients with irritable bowel syndrome are often depressed or anxious, ${ }^{3}$ have numerous other symptoms, ${ }^{4}$ and are reported to do well with psychotherapy. ${ }^{56}$ They are, incidentally, very prone to dyspareunia.

Maybe it is time gynaecologists and gastroenterologists got together (perhaps with psychiatrists and GPs) to explore the importance of this overlap and to draw up agreed guidelines for the doctor who is faced with a woman complaining of lower abdominal pain.

Department of Medicine,

$\mathrm{K}$ W HEATON

Bristol BS2 8HW

1 Thompson WG, Heaton KW. Functional bowel disorders in apparently healthy people. Gastroenterology 1980;79:283-8.

2 Manning AP, Thompson WG, Heaton KW, Morris AF. Towards positive diagnosis of the irritable bowel. Br Med f 1978;ii: 653-4.

3 Palmer RL, Stonehell E, Crisp AH, Waller SL, Misiewicz JJ. Psychological characteristics of patients with the irritable bowel syndrome. Postgrad Med f 1974;50:16-9.
4 Whorwell PJ, McCallum M, Creed FH, Roberts CT. Noncolonic features of irritable bowel syndrome. Gut 1986;27: $37-40$

Whitehead WE. Psychotherapy and biofeed-back in the treatment of irritable bowel syndrome. In: Read NW, ed. Irritable bowel syndrome. London: Grune and Stratton, 1985:245-63.

6 Whorwell PJ, Prior A, Faragher EB. Controlled trial of hypnotherapy in the treatment of severe refractory irritable bowel syndrome. Lancet 1984 ;ii: 1232-4.

\section{Recurring meningitis: beware the normal looking ear}

SIR,-Mr L Durham and colleagues ( 8 November, p 1230) highlight the difficulties of detecting the source of infection in recurring meningitis. Quite rightly, they warn against excluding an otological source of infection when there are no signs and symptoms of aural disease. But I was disappointed that they did not give more information on how to detect leaks of cerebrospinal fluid from the base of the skull.

The radiological investigations mentioned in the case reports are appropriate, but their major shortcoming is that they show anatomical detail at a time when the clinician is trying to diagnose a dynamic process - that is, a leak of cerebrospinal fluid. Computed tomography with intrathecal contrast is of only limited value. It detects only leaks that are sufficiently large so that contrast media is present outside the meninges when the scan is performed (usually within an hour of the intrathecal injection)

I have investigated seven patients with recurring meningitis over the past five years both in Bristol and at the Royal Free Hospital, London, for suspected leaks of cerebrospinal fluid from the base of the skull. In all save two of these computed tomography with intrathecal contrast did not reveal the leak. Scintigraphy is a valuable dynamic investigation and is much more sensitive at detecting slow leaks.

In conjunction with the medical physics department I use a technique of injecting indium-111 diethylenetriaminepentacetic acid (DTPA) after an initial scan. Four hours later, after another scan, the sphenoid sinus is washed out and the effluent sent for counting. At the same time six neurosurgical patties are inserted in the nose at selected sites. These are sent for counting two hours later. Finally the patient is scanned a further four times over the subsequent 48 hours. With this technique leaks have become apparent up to 30 hours after the initial injection of indium-111 DTPA. ${ }^{1}$

The patient with recurring meningitis but normal findings on ear, nose, and throat examination and tomography merits scintigraphy in an attempt to identify any leak of cerebrospinal fluid which may be amenable to surgical treatment.

Ear, Nose, and Throat Department,

MaURice HaWthorne

Bristol Royal Infirmary

Bristol 2

1 Hawthorne M, Num R. Self assessment in radiology 1; ear, nose, and throat. London: Wolfe Medical Publications, 1984:195-6.

\section{Differences between neurological and neurosurgical approaches in the management of malignant brain tumours}

SIR,-I have no doubts about the accuracy of the study by Dr S J Wroe and his associates but do take exception to their implied and stated conclusions.

They refer to "malignant brain tumours," meaning tumours (gliomas) which grow more rapidly than do others. There are no "malignant" gliomas in the sense that carcinomas and sarcomas 
are malignant. With very rare exceptions they remain localised. They do not spread to other parts of the body. They do not spread through the blood stream or the lymphatics as truly malignant tumours do.

Their study does not include truly aggressive neurosurgical procedures. No effort was made to remove the tumours completely, and only 19 of the 212 patients had even a craniotomy and decompression. Their suggestion for treatment of these tumours is, "We would like to suggest from our data that a conservative approach to management with steroids alone can be justified ethically.' If this suggestion is followed we will continue to do no better than neurologists and neurosurgeons have been doing for over 100 years - that is, we will continue to fall flat on our faces. All patients with cerebral gliomas will continue to die from their tumours. Unfortunately there will be a number of physicians and surgeons who will be influenced by this report and will not endeavour to deal more effectively with this problem.

This should not be the case. What can and should be done? Firstly, neurologists and neurosurgeons must endeavour to educate the genera medical profession about those symptoms which may indicate that patients are suffering from brain tumours. In the authors' study $95 \%$ of the patients had had such symptoms for from two to over 12 months. Obviously the tumours had grown larger during those months and invaded the surrounding brain more. Equally important, if we are to cure any of these tumours neurosurgeons must become more aggressive and attempt to remove these tumours completely. If this is done our patients will live longer and in better health and some of them will be cured. . $^{1-3}$

The surgical treatment of brain tumours had its beginning in Great Britain. I hope that it will continue to improve there and throughout the world. Improvement should not be retarded by studies and recommendations such as are to be found in this paper.

Paul C Bucy

Tryon,
NC 28782

USA

1 Jelsma R, Bucy PC. The treatment of glioblastoma multiforme of the brain. $\mathcal{f}$ Neurosurg 1967;27:388-400.

2 Jelsma R, Bucy PC. Glioblastoma multiforme. Its treatment and some factors affecting survival. Arch Neurol 1969;20:161-71.

3 Bucy PC, Oberhill HR, Siqueira EB, Zimmerman HM, Jelsm R. Cerebral glioblastomas can be cured! Neurosurgeny 1985;16 R. Cer 714 .

\section{Study of "discharge communications" from hospital}

SIR,-We found Dr R J Mageean's study disappointing for several reasons.

Firstly, we have shown the usefulness of the initial hospital discharge note (form HMR 2A, or local variant), and our study showed that this is quicker and better delivered by hand than sent by first class post-resulting in a median delay of $2 \cdot 5$ compared with $7 \cdot 5$ days. ${ }^{1}$ Dr Mageean reports that over half the patients had contacted their general practitioner after discharge before the general practitioner had received any information. With hand delivered notes, available to the general practitioner at the first contact with the patient, problems arose in only $5 \%$ of cases, ${ }^{1}$ compared with $38 \%$ when the note was posted. Moreover, a hand delivered note is available to whichever doctor first sees the patient, be he the patient's own doctor, a deputising service doctor, or the doctor of relatives with whom the patient may be convalescing.

Secondly, Dr Mageean aims to assess the adequacy of hospital communications, but his criteria do not do so. We showed that $95 \%$ of hand delivered notes and $62 \%$ of the posted notes arrived in time to avoid problems for the general practitioner. Some of the most rapidly delivered notes did not arrive in time to prevent problems, and some of the longest delays (up to 47 days) did not cause problems. This confirms our belief that when a case is delicate or needs particularly urgent or close cooperation the hospital doctor should speak to the general practitioner before discharge, if necessary by telephone. Such contacts are an important aspect of medical communication which Dr Mageean's study ignores. Dr Mageean states that there are no other published studies on this subject. Apart from our own there are several, both from general practice ${ }^{34}$ and from hospitals. ${ }^{56}$

Finally, as hospital doctors, we were saddened by the poor service that Dr Mageean appears to be receiving. This unit's better results may simply reflect a special interest in medical communica tion, possibly nurtured by the consultant's previous experience in general practice. Nevertheless, there can be little excuse for Dr Mageean not receiving any letter at all about $10 \%$ of his patients, or even for not receiving both a preliminary communication and a proper discharge letter about $48 \%$ of his patients. This study provides further ammunition for the case to improve medical secretarial services.

S B DOVER

Division of Medicine

Selly Oak Hospital,

Birmingham B29 6JD

T S LOW-BEER

1 Dover SB, Low-Beer TS. The initial hospital discharge note: sen out with the patient or post? Health Trends 1984;48:16.

2 Kessel N. Communication between GPs and hospital doctors. A hospital consultant's view. In: Walton J, McLachlan G, eds. Doctor to doctor-writing and talking about patients. London: Nuffield Provincial Hospitals Trust, 1984

3 Tulloch AJ, Fowler GH, McMullan JJ, et al. Hospital discharge reports: content and design. $\mathrm{Br}$ Med $\mathcal{f}$ 1975;iv:443.

4 Evans EO, McBride $K$. Hospital usage by a group practice. $f R$ Coll Gen Pract 1968;294:16.

5 Boyle CM, Young RE, Stevenson JG. General practitioners opinions of a new hospital discharge letter. Lancet 1974;ii:466.

6 Bado W, Williams CJ. Usefulness of letters from hospitals to general practitioners. Br Med f 1984;288:1813.

Non-invasive femoropopliteal assessment: is that angiogram really necessary?

SIR,-Mr C P Shearman and colleagues describe a system for determining the best site for dista anastomosis of femorodistal bypass without the use of arteriography (25 October, p 1086). The need for an inflow procedure was determined by preoperative palpation of the femoral pulse.

Several authors have found the femoral pulse to be unreliable in assessing aortoiliac disease. It may feel normal in $15 \%$ of patients with haemodynamically important aortoiliac disease,${ }^{1}$ and this may result from the presence of distal obstruction. We therefore rely on intra-arterial hyperaemic pressure measurement (the papaverine test) to reveal aortoiliac disease ${ }^{3}$ if arteriography is not performed. Such a test is also useful to reveal proximal disease not shown by arteriography.

The advent of percutaneous transluminal angioplasty as a therapeutic alternative has had a dramatic impact on clinical practice and in particular on the indications for arteriography. ${ }^{5}$ Arteriography may now be offered to patients, with symptoms which would not justify reconstrictive surgery, in the hope that the causative lesion may be suitable for angioplasty. ${ }^{6}$ If arteriography is avoided in patients with disease of sufficient severity to merit surgery then aortoiliac and possibly femoropopliteal lesions suitable for angioplasty will go unrecognised. Patients will be subjected to general anaesthesia for reconstructive surgery when success might have been achieved by the much simpler and less traumatic alternative of angioplasty. Up to $40 \%$ of such patients may be suitable for angioplasty. ${ }^{8}$

We would, therefore, be unwilling to plan treatment routinely for patients with peripheral vascular disease without performing arteriography.

A R BAKER

D S MACPHERSON

A Bolia

P R F BELL

Department of Surgery,

Leicester Royal Infirmary

Leicester LE2 7LX

1 Johnston KW, Demorais D, Colapinto RF. Difficulty in assessing the severity of aorto-iliac disease by clinical and arteriographic methods. Angiology 1981;32:609-14

Blaisdell FW, Gauder PJ. Paradoxical variation of the femora pulse in occlusion of the iliac artery. Surgery 1961;50:529-32.

3 Quin RO, Evans DH, Bell PRF. Haemodynamic assessment of the aorto-iliac segment. I Cardiovasc Surg 1975; 16:586-9.

4 Baker AR, Prytherch DR, Evans DH, Bell PRF Characterisation of Cardiovasc Res 1985;19:559-66.

Anderson JB, Wolinski AP, Wells IP, Wilkins DC, Bliss BP. The impact of percutaneous transluminal angioplasty on the The impact of percutaneous transluminal angioplasty on the manager.

6 Arfvidsson B, Davidsen JP, Persson B, Spangen L. Percutaneou transluminal angioplasty (PTA) for lower extremity arteria insufficiency. Acta Chir Scand 1983;149:43-7.

Campbell WB. Angioplasty for intermittent claudication BrMed f 1986;293:1047-8.

8 Doubilet P, Abrams HL. The cost of underutilization: percutaneous transluminal angioplasty for peripheral vascular disease. NEngl f Med 1984;310:95-102.

\section{Plasminogen activators in human colorectal} neoplasia

SIR,-Mr Graham Layer and colleagues (8 November, p 1241) have raised further points concerning our study of plasminogen activators in colorectal neoplasia (20 September, p 728)

We acknowledge that the cryofragmentation technique they originally described for the study of enzyme activity in neoplastic tissue has advantages over conventional homogenisation. We have found protein levels in carcinomas to be higher than in normal mucosa though by a factor of only $10 \%$. Goodman showed that wet weight was a more reliable denominator for the expression of colonic enzyme activity than protein content. ${ }^{1}$ We have found that enzyme activity expressed per ml of homogenate correlates with activity expressed per unit weight of protein for both normal mucosa and neoplastic tissue $(r>0.9, p<0.001)$. Enzyme activity was therefore expressed per $\mathrm{ml}$ of homogenate as this reflects wet weight. The fivefold decrease in tissue plasminogen activator activity and fourfold increase in urokinase activity in carcinomas compared with normal mucosa that we observed and the similar changes observed by others ${ }^{23}$ are thus unrelated to protein content.

We have observed similar urokinase activity in a squamous carcinoma of anus which had minimal tissue plasminogen activator whereas a single intestinal sarcoma had high tissue plasminogen activator but virtually no urokinase activity. Recent studies suggest that melanomas are associated with considerable tissue plasminogen activator but minimal urokinase activity ${ }^{4}$ (original reference 17). Perhaps therefore the plasminogen activator abnormality in a given neoplasm reflects its embryological origin.

Our theory of a role for urokinase in the adenoma carcinoma sequence was based on the particular biochemical properties of this enzyme, on the widely held view that urokinase plays a part in tissue degradation (original reference 9), and on established concepts of the importance of base- 